\title{
artículos
}

\section{Regina José Galindo o el cuerpo como nación}

\author{
Julia Ramírez Blanco
}

Investigadora vinculada a la Universidad Complutense de Madrid y

Residencia de Estudiantes

RESUMEN

El trabajo de la artista guatemalteca Regina José Galindo supone una denuncia reiterada de la violencia de género en América Latina. En el presente texto analizamos el conjunto de su obra, contextualizándola históricamente y situándola en el marco de lo político.

PALABRAS CLAVE: Regina José Galindo/ Fotografía/ Violencia de Género/ América Latina.

\section{Regina Jose Galindo or the Body as a Nation}

ABSTRACT

The work of the Guatemalan artist Regina José Galindo implies a reiterated denounce of gender violence in Latin America. In this text, we analyse the whole of her work, putting it into its historical context, and locating it in the realm of the political. America.

KEY WORDS: Regina José Galindo/ Photography/ Domestic Violence/ Latin

Una joven artista guatemalteca parecía irrumpir de repente en el panorama artístico occidental ganando el León de Oro de la 51 Bienal de Venecia. Tan sólo dos ediciones antes, su performance titulada Piel había formado parte del proyecto expositivo de Harald Szeeman: tras afeitarse todo el pelo del cuerpo, se paseó desnuda por las calles de Venecia. Desde este momento, sus performances violentas y autovejatorias no dejaron de verse cada vez más en los eventos artísticos, atrayendo una gran atención de crítica y público. Sin embargo, no parece haber habido una respuesta equivalente en el mundo académico. Por ello no deja de ser sorprendente que no se haya realizado hasta la fecha ningún estudio en profundidad acerca de su producción. Encontramos catálogos, numerosas entrevistas y artículos periodísticos y semiperiodísticos ${ }^{1}$, recogiéndose los más importantes en una monografía publicada por Vainilla edizioni en $2006^{2}$. Sin embargo, aún faltan artículos académicos que analicen desde un punto de vista histórico su trabajo. Empezr a llenar esta laguna es lo que nos proponemos con el siguiente texto.

La pregunta principal que nos plantea su trabajo es la de su relación con el body art histórico. ¿Hasta qué punto es su obra diferente de la de artistas como Ana

* RAMÍREZ BLANCO, Julia: "Regina José Galindo o el cuerpo como nación”, en Boletín de Arte, n 30-31, Departamento de Historia del Arte, Universidad de Málaga, 2009-2010, págs. 519-532. Fecha de recepción: Enero de 2010.

1 http://www.prometeogallery.com/artist.asp?lang=en\&art=1 (consultado: enero 2009).

2 AA.VV.: Regina José Galindo, Vainilla edizioni, Abissola Marina, 2006. 


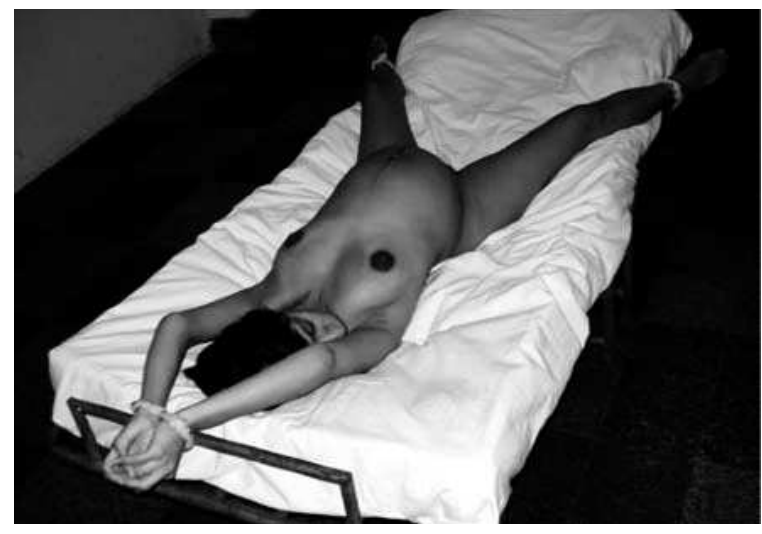

1. "Mientras ellos siguen libres" (2007).

Mendieta, Marina Abramovic o Chris Burden, también adeptos a la autovejación como práctica artística? ¿Qué significados peculiares adquiere la violencia en su obra? ¿Tiene alguna importancia el cambio del marco geográfico? Como performer, Galindo desde el principio se ha dedicado a realizar un concienzudo trabajo con su propio cuerpo, algo poco común en la tradición artística de su país ${ }^{3}$. En su trabajo realiza diversos tipos de agresiones sobre sí misma, a veces sola, o con ayuda de colaboradores ocasionales. Llevar la violencia omnipresente que existe fuera de la galería al interior mismo de sus paredes es una de las intenciones confesas. En sus obras, siempre documentadas mediante foto y vídeo, hará una suerte de inventario de suplicios, que es nuestra intención sistematizar y comprender.

\section{UN CATÁLOGO DE TORTURAS.}

Quizás el tema más recurrente en sus acciones sea la inmovilización violenta de un cuerpo. Este asunto se verá ya en una de las obras más tempranas, Dolor en un Pañuelo (1999), donde, según describe la artista desde su web, "amarrada a una cama vertical se proyectan sobre mi cuerpo noticias de violaciones y abusos cometidos contra la mujer en Guatemala"4. Aparece la denuncia de la violencia de género, algo que será un tema central de todo su trabajo. Y surgirá también una concepción básica para comprender el conjunto de su obra, la idea de que el maltrato de un solo cuerpo refleja todos los demás, la contemplación del dolor individual como punta de iceberg de un enorme dolor colectivo. El cuerpo de Galindo de alguna manera con-

3 CAZALI, Rosina: “( )golpes”, en AA.VV.: La Bienale di Venecia. 51. esposizione internazionale d'arte. Sempre un po' più lontano. Marsilio Editori, Venecia, 2005, pág. 106.

4 Salvo cuando se indique lo contrario, las descripciones de las performances están tomadas de la página web de la propia artista, donde también pueden encontrarse imágenes que documentan las acciones: http://www.reginajosegalindo.com (consultado: enero 2011). 
tiene todos los otros cuerpos de mujeres torturadas, algo explicitado mediante las noticias proyectadas sobre su piel. Esta idea podrá verse de manera omnipresente durante los años que sigan. Un cuerpo inmovilizado es todos los cuerpos inmovilizados.

Algunas obras implicarán el cuerpo embarazado de la propia artista. Un espejo para la pequeña muerte (2006) la muestra a tan sólo tres meses de dar a luz, "desnuda, atada de manos y pies, sobre un charco hecho con mis propios orines dentro de una pensión de mala muerte", recreando una brutal escena de maltrato. Mientras, ellos siguen libres [1], realizada sólo dos meses más tarde, ampliará este discurso acerca de la maternidad en los entornos de violencia: "permanezco atada a una cama-catre, con cordones umbilicales reales, de la misma forma que las mujeres indígenas embarazadas eran amarradas para ser posteriormente violadas durante el conflicto armado en Guatemala". A través de obras como ésta se da una radicalización muy politizada de las reflexiones acerca de la maternidad que hacían feministas estructuralistas como la artista Mary Kelly ${ }^{5}$. Ya no se trata de desmontar la mística de la maternidad

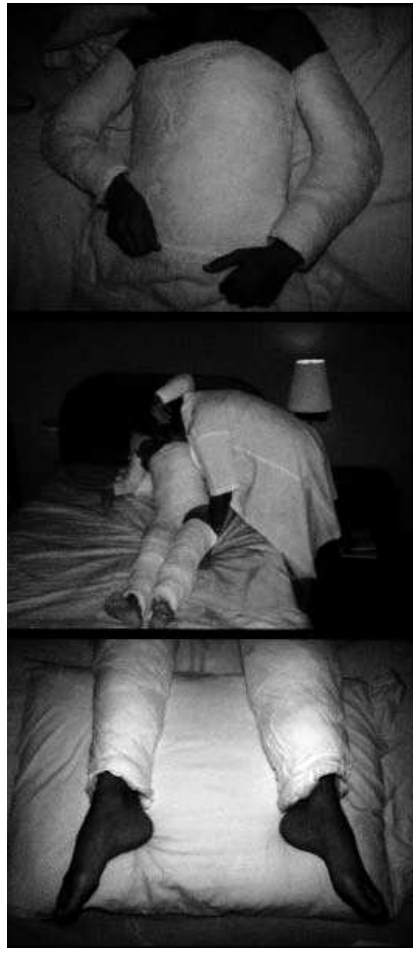

2. "Yesoterapia” (2006). utilizando las herramientas del psicoanálisis y un tono reflexivo y científico. Hay tan sólo una cruda exhibición de unas condiciones que pretenden ignorarse, la enorme violencia asociada al proceso de gestación para numerosísimas mujeres del mundo.

Digamos que Regina José Galindo realiza, de alguna manera, una crítica "materialista". Para ella la injusticia, la opresión y la desigualdad de género son, literalmente, violencia. Algo muy físico, palpable, que marca el cuerpo con heridas profundas. Esto se ve claramente en Yesoterapia (2006) [2], donde, sugiriendo la convalecencia posterior a una brutal paliza, Galindo estará completamente enyesada durante cinco días, incapaz de hacer nada por sí misma, y precisando el cuidado constante de una enfermera.

\footnotetext{
5 Mary Kelly en su compleja obra Post Partum Document, de 1974, "se propone problematizar el concepto mismo de maternidad, esto es, analizar cómo se construye socialmente el papel de la madre en la cultura patriarcal. Post Partum Document describe los pormenores de la relación entre Kelly y su hijo durante los primeros seis años de vida del niño". En MAYAYO, Patricia: Historias de Mujeres, historias del arte. Cátedra, Madrid, 2003, págs. 113-116.
} 


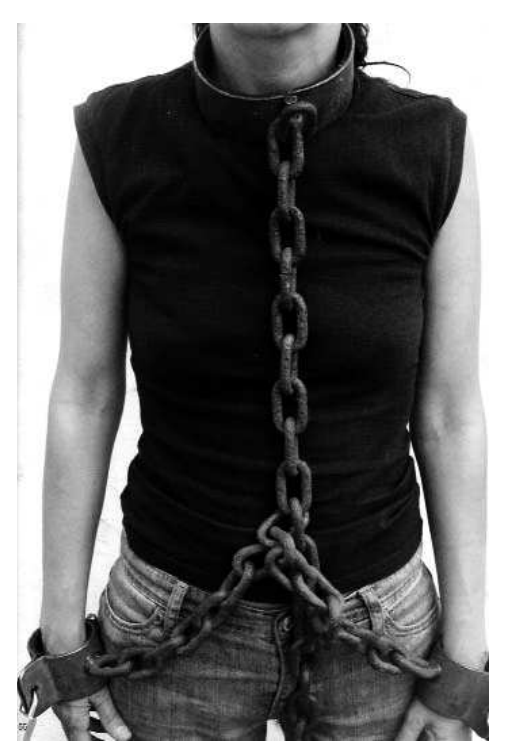

3. "Peso" (2006).

La violencia que fuerza al cuerpo a permanecer inmóvil no es desde luego un asunto del cual estén al margen los poderes represivos del estado. Estos son los agentes que se sugieren en Camisa de Fuerza, de 2006 ("permanezco con una camisa de fuerza durante tres días consecutivos, viviendo en un psiquiátrico de San Alexius"), Cepo, de 2007 ("permanezco doce horas detenida por un cepo"), o 150.000 voltios, realizada en 2007 ("recibo una descarga eléctrica de 150.000 voltios con un dispositivo eléctrico utilizado por la policía para detener sospechosos"). Peso (2006) habla de cómo la opresión dificulta enormemente el movimiento, haciendo extremadamente difícil realizar cualquier acción por trivial que sea: "permanezco encadenada y con grilletes de forma consecutiva durante cuatro días, realizando así mi vida cotidiana" [3]. Más recientemente en Libertad Condicional

(2009), se verá inmovilizada con siete cadenas y siete candados. De la privación de libertad habla también Juegos de Poder, del mismo año, donde la artista es hipnotizada por un célebre hipnotizador, que le da órdenes.

Íntimamente conectado con la inmovilización está el encierro, al que Galindo se someterá en diversas acciones. Todos estamos muriendo (2000), presenta a la artista enganchada a una bombona de oxígeno, dentro de un pequeño cubículo en las afueras del museo. En Proxémica (2003) será ella misma quien pondrá el último bloque de cemento que cerrará la suerte de zulo donde pasará la noche y parte del día. Toque de queda (2005) supondrá su encierro durante diez días en "un ejercicio de reflexión sobre lo que sucede al ser humano al ser privado de su libertad". La cárcel de America's Family Prision (2008) es mucho más concreta. Galindo la describe del siguiente modo: "rento una celda utilizada en exhibiciones dentro de la industria de prisiones privadas en los Estados Unidos. Tomando como modelo las celdas familiares de T. Don Hutto, la adecuo y la habito junto con mi bebé y mi esposo durante 24 horas. Al salir la puerta queda abierta y la celda es mostrada como objeto de arte".

Parece deducirse que la privación de la libertad, el encierro, el aislamiento son temas centrales. La terrible frustración de ser reducido a la quietud. De que drásticamente limitando su movimiento, se le arrebate al ser humano la posibilidad de disponer siquiera de su cuerpo. 


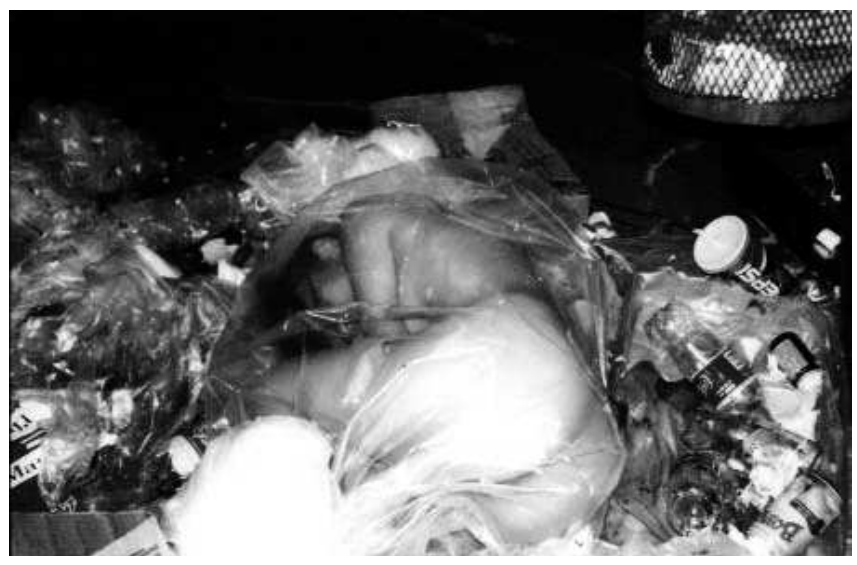

4. "No perdemos nada con nacer" (2000).

La tortura, por supuesto, es otro de los asuntos principales. Galindo recrea distintas formas de violencia estatal o "privada" en numerosas acciones. En Trayectoria (2008) un hombre arrastra a la artista cogiéndola del pelo, describiendo así una diagonal en el pavimento de la galería. El deseo de emparentar su cuerpo al de las mujeres maltratadas se verá claramente en el performance sonoro (279) Golpes, donde según la descripción de la artista, "encerrada en un cubículo, sin que nadie pueda verme, me doy un golpe por cada mujer asesinada en Guatemala del 1 de enero al 9 de junio del 2005. Amplifico el sonido, para que sea escuchado desde afuera". En el famoso vídeo Himenoplastia (2004) Galindo se somete ella misma a una tortura inducida por el patriarcado, la intervención quirúrgica "para volver a ser virgen". Con todo detalle, la operación fue filmada tras llegar a un acuerdo con el médico ${ }^{6}$.

Y estos dos ejes sobre los que gira la obra de Regina José que son la inmovilización y el maltrato confluirán naturalmente en lo que es la violencia final y la paralización definitiva: el asesinato. Asesinato que acaba con centenares de mujeres cada año en Guatemala.

Ya en el año 2000 Galindo había fingido su propia muerte, en la obra No perdemos nada con nacer. Desnuda, dentro de una bolsa de plástico transparente, fue

6 La operación, realizada en una clínica ilegal a la que llegó siguiendo un anuncio en el periódico, fue realizada en dudosas condiciones de seguridad. Cuando la artista volvía en coche desde dicha clínica, se produjo una terrible hemorragia, que obligo a llevarla a su ginecólogo, y de ahí al hospital. Véase GOLDMAN, Francisco: "Regina José Galindo", BOMB Magazine n 94, invierno de 2006, accesible en http://www.bombsite.com/issues/94/articles/2780 (consultado: enero 2011). 


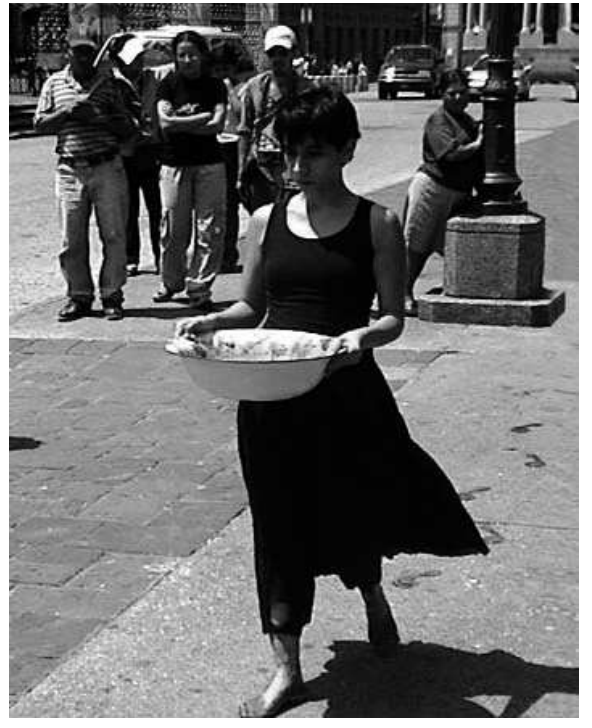

5. “Quién puede borrar las huellas”(2003).

depositada en el vertedero municipal de la ciudad de México, repitiendo posteriormente la acción en el de la ciudad de Guatemala [4]. Valium 10 $\mathrm{ml}$., también del 2000, presenta a la artista en una inconsciencia muy parecida a la muerte ("me inyecto 10 miligramos de Valium, permanezco sedada en el espacio de la galería"). Igualmente inmóvil, pero ahora sobre una camilla, en Tanatosterapia (2006) el rostro quieto de Galindo es acicalado por una maquilladora de cadáveres. De alguna modo ambas obras se combinarán en Reconocimiento de un cuerpo (2008), performance donde su cuerpo "permanece anestesiado en una camilla, desnudo, bajo una sábana blanca", esperando a que el público levante la tela tal y como sucedería en la morgue. Sobre los cuerpos que nunca llegan a ser reconocidos trata Tumba (2009), donde desde un barco se arrojan al mar siete bultos rellenos de arena de mar, de un peso similar al cuerpo humano, para hacerlos desaparecer, en una especie de reconstrucción de un momento posterior al asesinato.

\section{Las relaciones con el BODY ART...}

Todas estas obras desde luego nos ofrecen un cierto sabor a performance histórica. Ello sorprende, pues la radicalidad con la cual Galindo afronta el trabajo con su cuerpo parecía haber "pasado de moda" entre los artistas de su generación. Ella parece ser consciente: cuando cita a las figuras que le interesan e influyen, pronto afloran referencias a importantes figuras del Body Art de los setenta, como Marina Abramovic, Chris Burden, Ana Mendieta, Gina Pane. Su huella sobre la obra de la artista guatemalteca para algunos autores es excesiva ${ }^{7}$. Quizás resulta interesante dilucidar si Galindo aporta o no algo nuevo respecto a lo que ya se hizo en el Body Art histórico.

Como habían hecho los accionistas vieneses (destacando Günther Brus con

7 Véase VETROCQ, Marcia E.: "Venice Biennale, be careful what you wish for", Art in America, Septiembre 2005, en http://www.thecentreofattention.org/research/vartinamerica.html (Consultado: enero 2011). 
su famosa Prueba de Resistencia), o, con diferente intencionalidad, Abramovic, Pane o Burden, Regina José Galindo realiza una sistemática exploración del dolor sobre su propio cuerpo. A diferencia de muchas obras de los vieneses, en su trabajo la agresión física nunca es mera escenificación: siempre es realizada de manera real sobre el propio organismo. Una gran austeridad de medios otorga protagonismo absoluto a aquello que sucede en la piel del performer. Como estos artistas, para documentar sus obras Galindo utilizará sobrias fotografías o vídeos de aparente sencillez, que perduran como objetos susceptibles de ser expuestos en el museo o la galería.

El dolor en Galindo casi siempre nos habla de la violencia de género. En ese sentido entronca de manera clara con creadoras como Abramovic o Pane, que a menudo trataron un problema que había resultado de vital importancia para el feminismo de la Segunda Ola. Estos estrechos parentescos con el body art de los setenta son algo intencionado. Ello lo demuestran las numerosas citas a performances clásicas de los setenta, de las cuales está repleta su obra.

No perdemos nada con nacer (2000) remite al Dead Man de Chris Burden (1972), donde éste se metió en un saco como si fuera un cadáver. Sin embargo, y a diferencia de lo que sucedía con la obra de este artista norteamericano, el cuerpo inmóvil de Regina, en posición fetal y dentro de una bolsa de plástico, no es abandonado en una autopista. Es depositado en un vertedero, como los centenares de mujeres asesinadas cada año en Guatemala, deshechadas cual "despojo humano" [4].

Las heridas que Gina Pane fijaba en yeso y de algunas obras de Mendieta relacionadas con la sangre, están seguramente en la génesis iconográfica de ¿Quién puede borrar las huellas?, de 2003: una "caminata de la Corte de Constitucionalidad hasta el Palacio Nacional de Guatemala, dejando un recorrido de huellas hechas con sangre humana" [5]. Sin embargo, aquí ya no hay una exploración del dolor, pues éste se conoce de sobra. Las pisadas sangrientas de Galindo suponen una denuncia "en memoria de las víctimas del conflicto armado en Guatemala, en rechazo a la candidatura presidencial del ex-militar, genocida y golpista Efraín Ríos Montt", una reivindicación del recuerdo de la sangre guatemalteca derramada. Los cortes con cuchilla de Pane o los de Abramovic de nuevo serán revisitados, tomando la forma de letras fuertemente connotadas en Perra (2005), donde Galindo se escribirá a cuchillo esta palabra sobre su muslo derecho, en "denuncia de los sucesos cometidos contra mujeres en Guatemala, donde han aparecido cuerpos torturados y con inscripciones hechas con cuchillo o navaja" [6].

La célebre obra Rape Scene de Ana Mendieta (1973), en la cual la artista preparó una compleja escenografía para recrear su propia violación que incluía su cuerpo atado y ensangrentado, es de algún modo evocado en Mientras, ellos siguen libres (2007) [1]. En ella, Galindo se hizo atar con cordones umbilicales al cabecero 
y los pies de una cama, con las piernas abiertas, como si estuviese a punto de ser violada (¿quizás por el espectador?). El momento recreado es justo el anterior al que sugería Mendieta, y la metodología de la agresión es muy concreta, pues, como ya vimos, sigue "la misma forma que las mujeres indígenas, embarazadas, eran amarradas para ser posteriormente violadas durante el conflicto armado en Guatemala". A su vez, la mujer desnuda, atada de manos y pies nos remite a la acción Tied-Up Woman, también de Mendieta, realizada en la Universidad de lowa, en 1973.

A un nivel más general, la vulnerabilidad que el cuerpo de la artista presenta en muchas acciones, expuesto a la posible violencia del espectador recuerda a algunas obras de Marina Abramovic, como la célebre Ritmo 0 (1974), donde ésta dispuso 72 objetos que podían ser usados por el espectador sobre el propio cuerpo de la artista, de la forma que deseasen. Sus abundantes encierros remiten a la primera performance de Chris Burden, realizada en 1971, durante la cual permaneció cinco días en una taquilla, o a algunos trabajos del italiano Vito Acconcci, aunque éstos fuesen siempre más lúdicos.

A pesar de que todas estas obras contienen citas muy claras, en una línea que quizás se relacione con las estrategias del apropiacionismo artístico, resulta indiscutible que en ningún caso se trata de una simple repetición del trabajo ajeno. Siempre puede observarse un proceso de relectura, que reubica la violencia a la que se refieren las piezas de los setenta dentro del contexto específico de las agresiones locales, convirtiendo su dolor en el de América Latina, en el dolor concreto de Guatemala. Aunque como muchos artistas históricos, la guatemalteca declare "investigar su propia resistencia", ello es una parte marginal de su trabajo, que funciona sobre todo a nivel personal. Lo que busca con su proceso de auto-tortura es hacer visibles las vejaciones contra las mujeres cometidas en una zona geográfica determinada, marcada por procesos históricos concretos. Galindo coincide con la visión de la violencia de género de teóricas del feminismo radical como la norteamericana Kate Millet, para las cuales éste es un problema estructural, que se sitúa en la base misma del sistema. Sin embargo la guatemalteca no se refiera al patriarcado en general, sino al peculiar sistema patriarcal, marcado por la militarización y la violencia, que existe en su país, Guatemala, donde las cuestiones de raza, sexo y clase son indisociables, tal y como había señalado el feminismo poscolonial. Digamos que la diferencia fundamental respecto al Body Art está en el grado de concreción de la violencia a la que se refiere. Para Galindo, respecto al Body art, "el momento es diferente, y eso ya marca la diferencia"8. El momento, y, sobre todo, el lugar.

8 DE GRACIA, Silvio: “Regina José Galindo en Cordoba, Argentina”, Escáner Cultural. Revista virtual de arte contemporáneo y nuevas tendencias, 2008, en http://revista.escaner.cl/node/1063 (consultado: enero 2011). 
VIOLENCIA HISTÓRICA, VIOLENCIA NACIONAL.

Para Galindo, Guatemala es la justificación y la causa misma de su obra. Numerosas declaraciones resultan muy claras al respecto: "lo que yo trabajo es tan radical porque soy guatemalteca. Surge de dónde procedo, de qué estoy hecha, de qué imágenes estoy formada. Todo responde a que soy guatemalteca, si hubiera nacido en otro punto del mundo definitivamente mi obra sería distinta"9. Afirma ser incapaz de separarse emocionalmente de aquello que sucede en su país ${ }^{10}$, que en uno de sus poemas denomina su "campo de batalla"11. Si su trabajo es "visceral y violento" ello se debe a la naturaleza de "la realidad guatemalteca, del contexto latinoamericano" al que se refieren todas sus obras. "Porque esta realidad es violenta. $Y$

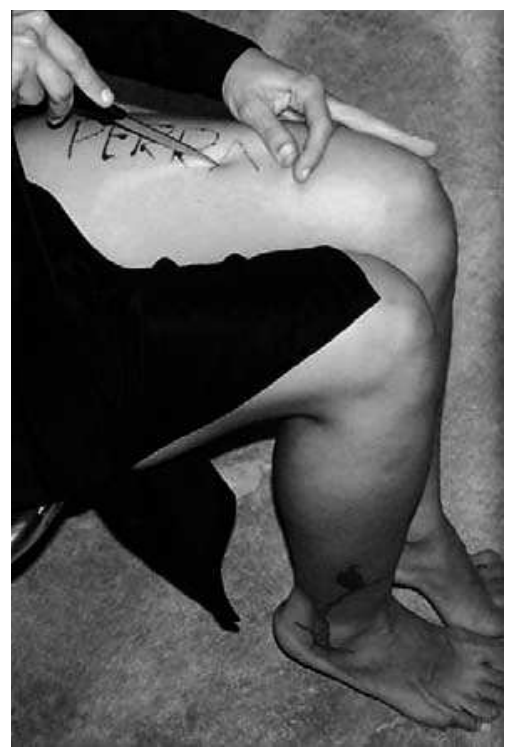

6. "Perra"(2005). ya nadie se conmueve" 12 .

Las performances surgirán de su dolor y su rabia, y a través de ellas intentará canalizar esa energía para convertirla en algo "más colectivo"13. Está siempre presente la conciencia de las raíces de todo ese sufrimiento, profundamente hundidas en la historia del país, en una reivindicación de la historia en la que coincide con numerosas figuras del mundo cultural guatemalteco, que también reclaman la memoria de los crímenes. Por citar sólo unos pocos nombres, personas como la conocidísima Rigoberta Menchú, la pintora Isabel Ruiz o el cineasta Mario Roberto Morales $^{14}$, con el que colaboró Galindo en el cortometraje Amorfo-Te busqué15, trabajan para mantener viva la conciencia del pasado. Uno de los elementos que explica la obra de Galindo es que, como dice Contreras, pertenece a una sociedad hon-

9 GUTIÉRREZ, Alejandra V.: “Regina Galindo”, Este país, 2008, en http://www.este-pais.com/?q=node/87 (consultado: noviembre 2008).

10 GOLDMAN, Francisco: op. cit.

${ }_{11}$ Dicho poema puede encontrarse en el blog literario de la artista: http://reginajose.blogspot.com/2005_07_01_archive.html (consultado: enero 2011).

12 GUTIÉRREZ, Alejandra V.: op. cit.

13 GOLDMAN, Francisco: op. cit.

14 CONTRERAS, Ana Y.: "Memoria, pasado y presente en "Amorfo-te busqué", un cortometraje de Mario Rosales", A contra corriente, Vol. 5, No. 3, Carolina del Norte, 2008, págs. 170-184.

15 Véase la página web del film: http://www.amorfo-tebusque.com/espaniol.htm (consultado: enero 2011). 


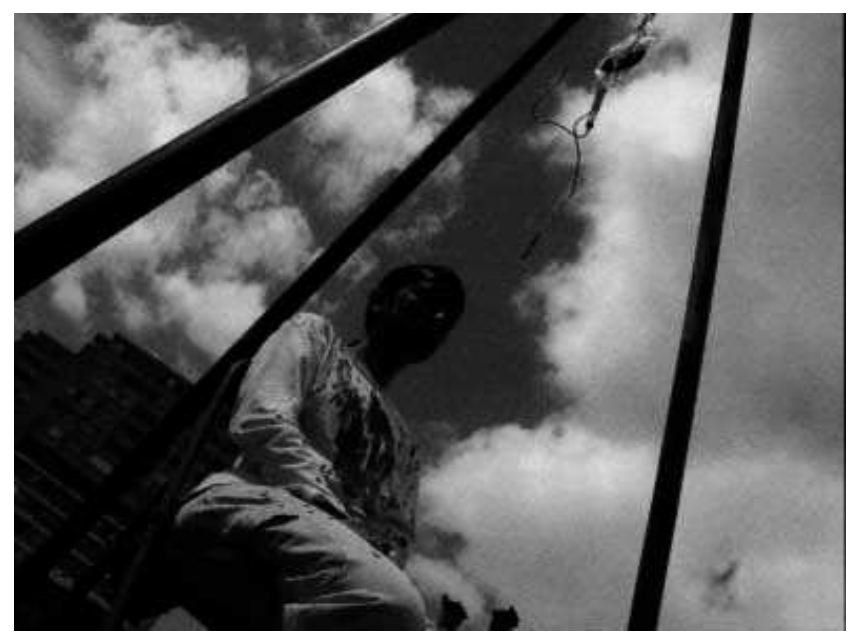

7. "El peso de la sangre"(2004).

damente marcada por un trauma sin resolver ${ }^{16}$. Los genocidas del pasado siguen presentes en la organización del sistema, aunque desde una cierta oscuridad, y buscando siempre lograr la amnesia de los ciudadanos. En 2003 esto pudo verse con una claridad demasiado meridiana, cuando se produjo la aceptación de la candidatura presidencial del golpista Efraín Ríos Montt.

Galindo, como muchos otros, comprende que la herencia de caos, injusticia, opresión y violencia seguirá omnipresente hasta que no se condene a los responsables y se modifique la estructuración misma del sistema. Su obra habla del pasado porque todavía es presente. Y se refiere a menudo a la Guerra Civil porque ésta educó a toda una sociedad en la violencia extrema contra las mujeres pues, en palabras de Lucía Muñoz y Michael Parenti, los asesinos "hace algunos años desarrollaron el gusto por infligir violaciones, torturas y asesinatos al servicio de su país"17. Obras como Mientras, ellos siguen libres [1], que recrean el sistema para violar mujeres que fue utilizado durante la Guerra Civil, evidencian el origen histórico de una "metodología" de la agresión que se sigue practicando. En El Peso de la Sangre (2004) [7], un litro de sangre humana cae gota a gota sobre la cabeza de Galindo, sentada en la Plaza Central de Guatemala, centro simbólico del país, en una metáfora de la enorme cantidad de sangre derramada que pesa inevitablemente sobre la existencia en Guatemala.

16 CONTRERAS, Ana Y.: op. cit., págs. 170-184.

17 MUÑOZ, Lucía y PARENTI, Michael: "Gender Savagery in Guatemala”, Global Research,13 de julio de 
Ya sin remitirnos al pasado, ya en el periodo "democrático" la extensión de la violencia de género es abrumadora en este país, con una estadística de asesinatos que va cada año en aumento, con una tasa de homicidios seis veces mayor que el promedio ${ }^{18}$. Resulta aterrador leer informaciones como los que nos proporcionan Muñoz y Parenti, informándonos de que "investigadores independientes denuncian que la gran mayoría de las atrocidades de hoy en día contra las mujeres ha sido cometida por los actuales o últimos miembros de los servicios de inteligencia de Guatemala"19. Según se nos dice en este texto, las autoridades apenas manifiestan interés por descubrir los causantes de los crímenes, mostrando una implícita complicidad 20 . Esta información adquiere una terrible coherencia tras saber que las víctimas generalmente provienen de familias de baja renta, que fueron desplazadas de sus casas durante la guerra civil. Según Muñoz y Parenti, no sólo la impunidad de los crímenes, sino su existencia misma está relacionada con la clase y la raza de las víctimas, pues su asesinato formaría parte de una extensa "limpieza social", que afectaría también a otros estratos de la sociedad, como los niños de la calle. La sociedad guatemalteca espera que la primera ley de violencia de género promulgada en 2007 por el gobierno de Álvaro Colom Caballeros, (del partido Unidad Nacional de la Esperanza (UNE)), suponga un cambio en este panorama.

Puede que estas disgresiones parezcan arbitrarias, pero no lo son, pues están íntimamente relacionadas con la vida y la obra de Galindo como artista plástica y poeta. A menudo habla de esta omnipresencia de la violencia y la muerte en la cotidianeidad guatemalteca: "yo he visto muchos muertos en Guate, cosas terribles en Guate, hasta yo estoy acostumbrada. Estamos más enfermos que el resto de las sociedades. Esta descomposición social es como un cáncer". En este país "de eterna violencia" puede verse cómo "la muerte sucede a cada minuto, no puede maquillarse, está siempre allí, presente"21. Según relata, decidió marcharse por un tiempo a la República Dominicana tras ver las piernas descuartizadas de una mujer dentro de una caja en la calle, cerca de su casa de Guatemala, un hallazgo terrible al que nadie prestaba la menor atención ${ }^{22}$. Su poema Aquí realiza una síntesis de su manera de vivir la situación de su país. Tras una larga letanía de prohibiciones ("Aquí no se habla/Aquí no se opina/Aquí no se sueña/Aquí no se lee/Aquí no se ve...") concluye diciendo "Aquí sólo se muere/Aquí sólo se mata"23. Esta visión de su país es la misma que se encuentra en su obra plástica, donde el feminicidio es uno de los

2007, en http://www.globalresearch.ca/index.php?context=va\&aid=6314 (consultado: enero 2011).

18 Véase CARRILLO-FLÓREZ, Fernando: "Seguridad Ciudadana en América Latina: un bien público cada vez más escaso", en Pensamiento Iberoamericano. Nueva época, Nª 0, febrero de 2007, págs. 179-196.

19 MUÑOZ, L. y PARENTI, M.: op. cit.

20 Ibídem.

21 AA. VV.: Regina José Galindo... op. cit., pág. 59.

22 GUTIÉRREZ, Alejandra V.: op. cit.

23 AA. VV.: Regina José Galindo... op. cit., págs. 170-171. 
asuntos principales, englobado dentro del gran tema de la violencia y la opresión en Guatemala.

Este discurso centrado en una problemática propia de su lugar de nacimiento hace que casi podamos hablar de un arte nacional, aunque contrario a la tradicional concepción panegírica del mismo, puesto que muestra un marcado carácter elegíaco. Ello hace que desde el punto de vista de la recepción por parte de Occidente su obra quede parcialmente inserta en el contexto de la proliferación de discursos locales que configuran el mosaico de un arte multicultural, casi una moda crítica en el mal llamado Primer Mundo. Sin embargo, su visión es tan fuertemente política que escapa de la línea oficial, más amable y propensa a un exotismo complaciente. Resulta de gran dureza pues una de las cosas que hace es mostrar la extensión de la injusticia y la violencia.

\section{Corporizando Guatemala...}

Si Galindo representa a su país a través de su cuerpo de mujer, ello nos trae a la mente un viejo topos de la historia del arte, el de las alegorías nacionales. En ellas, siempre una figura femenina llevaba los atributos de un cierto lugar, que simbolizaba en una personificación idealizada cuyo origen se encuentra en el mundo romano, donde las monedas representaban a menudo las diferentes provincias del Imperio. Este tema, que renacerá con especial fuerza en la pintura a partir de la revolución francesa, con la famosa Marianne que representaba Francia, llegaría hasta el siglo XIX, con pinturas como la célebre alegoría de Italia y Germania de Johann Friedrich Overbeck (realizada entre 1811 y 1828). En América Latina adquirirá unas connotaciones muy concretas, con las alegorías de América hechas durante el período colonial ${ }^{24}$, donde se ven indios representando el exotismo y la abundancia de las lejanas tierras. Y, aunque el trabajo de Galindo se relaciona con toda esta tradición, la performer utiliza un enfoque totalmente opuesto.

El símbolo incorpóreo se convierte en un cuerpo real, contingente, que a la vez que genérico es terriblemente concreto. Y si las alegorías representaban el ente abstracto de un país, Regina representará los millones de cuerpos concretos que habitan y han habitado Guatemala. Unos cuerpos llenos de heridas y preñados de una muerte sembrada por la opresión. Su reflejo no puede tener nada de ideal.

Si para ella su propio organismo es "su vehículo", a partir del cual lo hace todo 25 , su utilización del cuerpo es siempre "para que éste sea reflejo de otros cuer-

24 FLORESCANO, Enrique: “Alegorías de la Patria en el Virreinato”, México D.F., 2004, en http://www.jornada.unam.mx/2004/06/17/ima-alego.html (consultado: diciembre 2011).

25 GUTIÉRREZ, Alejandra V.: op. cit. 
pos". Aunque la frase nos recuerda mucho a la famosa declaración de Gina Pane: ("yo, la artista, soy los otros"), para Galindo esos "otros cuerpos" están claramente definidos. Son los de las otras mujeres que viven y mueren en Guatemala. Galindo quiere utilizar su cuerpo "como un reflejo de lo que sucede en Guatemala a grandes magnitudes".

El tipo de arte nacional que realiza toma así la forma de un retrato. Un retrato del cuerpo de Guatemala, y de las diferentes formas que éste adopta. En la obra Zopilote, ave nacional (2005), desnuda, Galindo despluma a este, hasta quedar los dos tan solo protegidos por su piel. Si formalmente la pieza nos recuerda bastante a Muerte de un pollo de Ana Mendieta (1972), donde la cubana decapita un pollo y lo deja desangrarse a la altura de su pubis, esta obra es muy distinta. En ella, hay una equiparación del cuerpo de la mujer y el cuerpo de la nación, simbolizada por el zopilote. Tras realizar la acción, la mujer y el ave están igualmente desnudos e indefensos, el ave nacional es un ave desplumada, vejada como lo está la mujer guatemalteca. El cuerpo de Guatemala es un cuerpo de mujer. A través de sus performances el organismo individual de Regina José Galindo adopta las formas plurales de los cuerpos de su país, que retrata sobre su propia piel. Será literalmente el cuerpo de su país.

Y ese cuerpo es fundamentalmente un cuerpo maltratado. Las diversas vejaciones que antes hemos tratado de sistematizar se refieren a las diferentes formas de maltrato al que son sometidas las mujeres de su país. Palizas, violaciones, encierros, asesinatos... Y globalmente una impotencia que impide actuar, una inmovilización forzosa que hace que cueste mover los miembros.

Frente a esta violencia, el cuerpo que no está herido ha de estar forzosamente dormido. En Valium 10m/ el cuerpo drogado de la artista respondía a una pregunta que se planteaba desde la muestra, llamada Vivir aquí acerca de qué significaba vivir en un país como Guatemala. La respuesta de Galindo, que se inyectó diez miligramos de valium y exhibió su cuerpo inerte se refería a una frase de Miguel Ángel Asturias: "en este país sólo se puede vivir bien borracho o inconsciente". Así vemos que uno de los posibles cuerpos de Guatemala es un cuerpo ciego, sordo y quieto. Tan inconsciente que parece estar muerto.

A través de la obra de Galindo el país es encarnado, y adquiere un cuerpo. Un organismo femenino, con sangre indígena. Un cuerpo continuamente sujeto a vejaciones y martirios, que incesantemente marcan su relieve. Es un cuerpo casi siempre inmovilizado con violencia, o anestesiado por el miedo. Un cuerpo perpetuamente amenazado con el asesinato. El cuerpo se erige en una nueva geografía. 


\section{Conclusiones.}

Así, llegamos a la conclusión de que anunque formalmente la obra de Galindo se aproxime mucho al body art histórico, su sentido es muy distinto. Su arte es un arte político de un marcado carácter nacional, a diferencia de lo que sucedía con el body art de los años 60 y setentea, cuyo sentido no tenía relación con los discursos nacionales. La producción de Galindo configura un retrato que es una corporización de Guatemala, a través de un cuerpo indígena herido, inmovilizado, incluso asesinado. Un retrato que pretende ser una constatación y una denuncia.

El carácter literal, anti-teatral de sus performances que a menudo implican recreaciones reales de situaciones de violencia refleja lo materialista de su denuncia. Ella se refiere a la violencia insoportable de la opresión a la mujer en Guatemala. Una violencia real, física, sin nada de figurado o simbólico. La violencia de la tortura, la violación y el asesinato. Una brutalidad inseparable de la historia concreta del país, y ligada a nombres concretos de culpables que siguen libres.

Regina José Galindo afirma tener "la certeza de que el arte no cambia el mundo"26. Sus geografías nos revelan una cartografía de las heridas nacionales, del dolor inflingido, que son consecuencia directa de todo un sistema sociopolítico. Un dolor cuyas causas sólo se pueden eliminar políticamente.

\footnotetext{
26 Ibídem.
} 